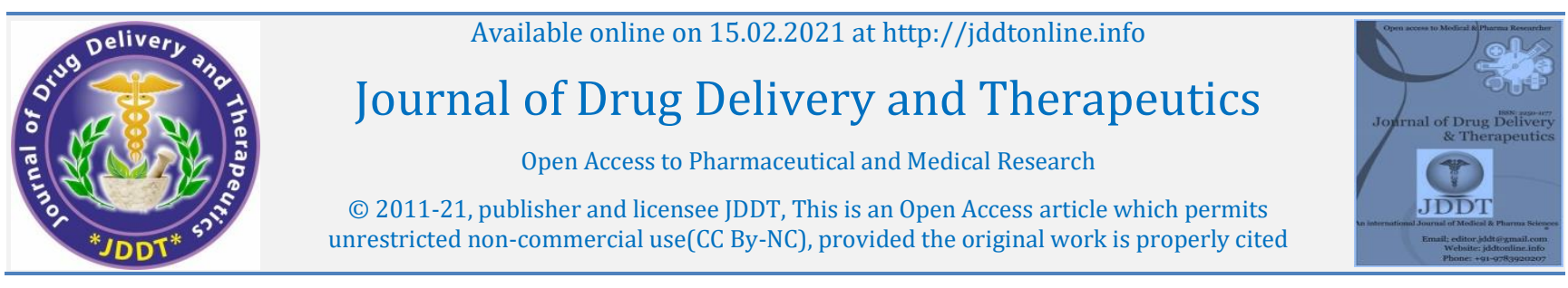

Open Access Full Text Article

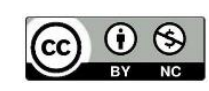

Review Article

\title{
A Review on Therapeutic Uses of Terpenoids
}

\author{
B. S. Bisht ${ }^{*}$, Harshita Bankoti2, Tanuja Bharti² \\ ${ }^{1}$ Assistant Professor Department of Chemistry Govt. P G College, Berinag, Pithoragarh, Uttarakhand, India
}

${ }^{2}$ M.Sc. Student Department of Chemistry Govt. P G College, Berinag, Pithoragarh, Uttarakhand, India

Article Info:

Article History:

Received 04 Dec 2020;

Review Completed 13 Jan 2021

Accepted 20 Jan 2021;

Available online 15 Feb 2021

\section{*Address for Correspondence:}

Dr. B. S. Bisht, Assistant Professor Department of Chemistry Govt. P G College, Berinag, Pithoragarh, Uttarakhand, India

\author{
Abstract
}

Terpenes are a huge and assorted class of natural mixes, created by an assortment of plants, especially conifers, other plants and by some insects. Terpenes regularly have a solid smell and may ensure the plants that produce them by deterring herbivores and by pulling in hunters and parasites of herbivores. Terpene are the essential constituents of the basic oils of numerous kinds of plan Essential oils are utilized generally as aromas in perfumery and for example, fragrant healing. Manufactured varieties and subsidiaries of regular terpenes extraordinarily extend the assortment of fragrances utilized in perfumery and flavors utilized in food added substances.

Keywords: Terpene, Medicinal, Therapeutic.

Cite this article as:

Bisht BS, Bankoti H, Bharti T, A Review on Therapeutic Uses of Terpenoids, Journal of Drug Delivery and Therapeutics. 2021; 11(1-s):182-185 DOI: http://dx.doi.org/10.22270/jddt.v11i1-s.4523

\section{Introduction:}

Terpenes, otherwise called isoprenoids are the biggest and most different gathering of normally happening exacerbates that are generally found in plants however bigger classes of terpenes, for example, sterols and squalene can be found in creatures. They are liable for the scent, taste, and color of plants. Terpenes are characterized based on association and number of isoprene units it contains. An isoprene unit is a structure square of terpenes that is a vaporous hydrocarbon that contains the atomic equation $\mathrm{C}_{5} \mathrm{H}_{8}$. Terpenes and terpenoids are terms that are frequently utilized reciprocally however the two terms have slight contrasts; terpenes are a course of action of isoprene units that are normally happening, unpredictable, unsaturated 5 -carbon cyclic mixes that emit a fragrance or a taste to protect itself from creatures that feed off of particular kinds of plants. Terpenes have numerous capacities in plants, for example, a thermoprotectant, flagging capacities, and not restricted to, shades, seasoning, and solvents yet in addition have different restorative uses ${ }^{1}$.

Terpene is a characteristic compound with different clinical properties and found in the two plants and creatures. Among regular items that intercede adversarial and advantageous associations inside the living being, terpene assume an assortment of jobs. Terpene ensures many living life forms like microorganisms, creatures and plants from abiotic and biotic burdens. Terpene can avert microorganisms, hunters, and contenders. Living creatures use terpene for numerous reasons like therapeutic purposes and correspondences about food, mates, or foes. It is noteworthy how various creatures use terpene for regular purposes despite the fact that terpene contain numerous structures and assortments ${ }^{2}$. So far just a little level of terpene is explored. Cannabis is quite possibly the most well-known hotspots for the therapeutic terpene. This plant contains numerous therapeutic properties like anticancer, antimicrobial, antifungal, antiviral, antihyperglycemic, pain relieving, mitigating, and antiparasitic. Terpene is likewise used to improve skin infiltration, forestall provocative illnesses. These days present day medicine utilizes huge sizes of terpene for different treatment drugs ${ }^{3}$. There are usually utilized plants like tea (Melaleuca alternifolia), thyme, Cannabis, Salvia lavandulifolia (Spanish sage), citrus organic products (lemon, orange, mandarin) and so forth that give wide scope of restorative qualities. Tea tree oil has expanded in fame as of late with regards to elective medication ${ }^{4}$. Tea tree oil is unpredictable basic oil and is acclaimed for its antimicrobial properties, and goes about as the dynamic fixing that is utilized to treat cutaneous contaminations ${ }^{5}$. Apart from the flavor that provides for food, fundamental oil contains antimicrobial properties. Thyme is one of plants that combine terpene alcohols and phenols which contain ground-breaking antibacterial and antifungal properties. Terpene incorporated from cannabis likewise since quite a while ago filled in as drugs. They likewise contain psychoactive properties and utilized against numerous irresistible infections ${ }^{6}$. 


\section{BIOSYNTHETIC PATHWAY OF TERPENES:}

The formation of the common isoprene-derived subunit has been extensively studied leading to a generally accepted pathway from acetate activated as acetylcoenzyme A (2), via acetoacetyl-coenzyme A (3), 3-hydroxy-3-methylglutarylcoenzyme A (5), and mevalonate (7) to isopentenyl diphosphate (IPP) (10), the first precursor possessing the branched $\mathrm{C}_{5}$-isoprenic skeleton 7,8 (Fig. 1). A few years ago, however, incorporation of ${ }^{13} \mathrm{C}$-labeled acetate and glucose into triterpenoids of the hopane series and the prenyl chain of ubiquinone from several bacteria proved unambiguously that the classical acetate / mevalonate pathway was not operating in all living organisms and that the isoprenic skeleton can be formed from triose phosphate derivatives via a non-mevalonate pathway ${ }^{9-11}$. Through the incorporation of [1-13C] and [U-13C6] glucose that monoterpenoid essential oils (geraniol, menthone, pulegone, thymol) are biosynthesized in plants by a pathway which is different from the established mevalonic acid route ${ }^{12}$.

\section{The mevalonate pathway:}

The mevalonate pathway involves the enzymatic condensation of two molecules of acetyl-CoA (2) by acetoacetyl-CoA thiolase to form acetoacetyl-CoA (3) (Figure 1). This reaction is followed by a nucleophilic attack of the acetyl-S-enzyme (4) derived from acetyl-CoA (2) to subsequently form 3-hydroxy-3-methylglutaryl-CoA (HMGCoA) (5) by the enzyme HMGCoA synthase. The enzyme HMG-CoA reductase (HMGR) catalyses the reductive deacylation of HMG-CoA (5) to mevalonate (MVA) (7) via mevaldate (6) and employs two equivalents of NADPH as reductant. This is followed by mevalonate kinase catalyses of the first ATP-dependent phosphorylations of mevalonate (7) to mevalonate 5-phosphate (8). Subsequently, mevalonate 5diphosphate (9) is produced by the further action of phosphomevalonate kinase. These reactions lead to the formation of isopentenyl diphosphate (IPP) (10). The IPP isomerase catalyses the 1,3-allylic rearrangement reaction converting IPP (10) into dimethylallyld iphosphate (DMAPP) (11), IPP and DMAPP being the biogenetic isoprene units $^{13}$ (Figure 1)
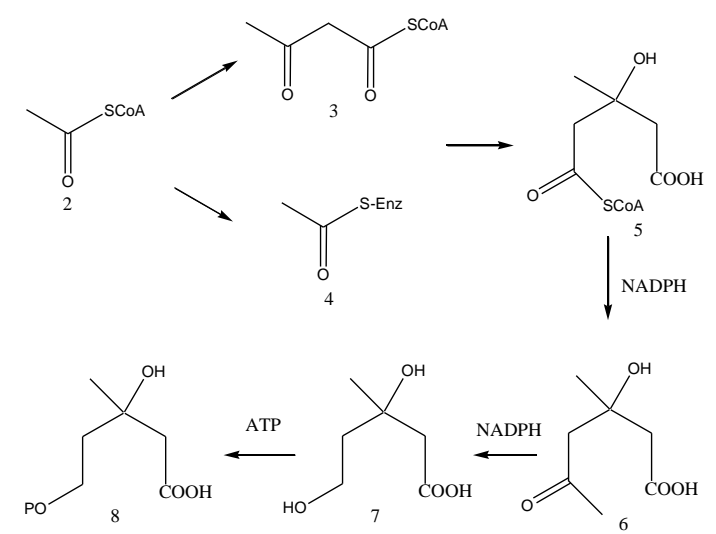

$\downarrow$ АTP

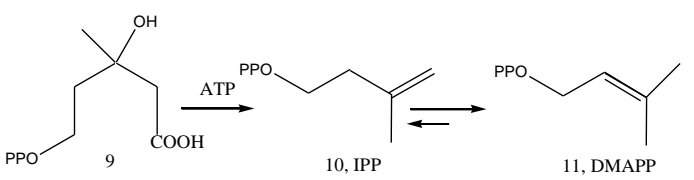

Figure 1: Mevalonate pathway

\section{The non-mevalonate (deoxyxylulose phosphate) pathway:}

Considerable evidence has now accumulated that the mevalonate pathway is employed much less frequently in the biosynthesis of terpenoids than is the newly discovered mevalonate independent pathway via 1-deoxyxylulose 5phosphate. The preliminary reactions in mevalonateindependent pathway involve the reaction of pyruvate (12) with thiamine diphosphate (13) to form pyruvate-thiamine diphosphate complex (14) which undergoes decarboxylation to generate (hydroxethyl) thiamine diphosphate (15). The first reaction of this pathway is a transketolase-like condensation between pyruvate (12) and D-glyceraldehyde 3-phosphate (16) to form 1-deoxy-D-xylulose 5-phosphate (DXP) (17). This involves condensation of (hydroxethyl) thiamine diphosphate (15), derived from pyruvate (12), with the aldehyde group of glyceraldehyde 3-phosphate (16). DXP (17) is then transformed into 2-C-methyl-D-erythritol-4phosphate (MEP) (18). The anticipated intermediate aldehyde (2-C-methylerythrose-4-phosphate) (19) is not released from the enzyme but is simultaneously reduced by NADPH. Subsequent reactions lead to the formation of isopentenyl diphosphate (IPP) (10) and DMAPP (11). In contrast to the mevalonate pathway, where IPP (10) isomerized to DMAPP (11), this last isomerization is yet to be confirmed as there is growing evidence that it may not occur in the non-mevalonate pathway ${ }^{10}$. (Figure 2)

Moreover, the non-mevalonate pathway for isoprenoid biosynthesis has been confirmed in several bacteria ${ }^{10-11}$ and recently for the biosynthesis of diterpenoids in two higher plants, Gingko biloba and Salvia miltiorrhiza as well as for the formation of all isoprenoids (i.e. sterols, prenylquinones, phytol and carotenoids) of the unicellular green algae Scenedesmus obliquus. Several terminologies commonly in use for this pathway include mevalonate-independent pathway, glyceraldehyde 3-phosphate / pyruvate pathway, deoxyxylulose phosphate (DXP or DOXP) pathway, and methylerythritol phosphate (MEP) pathway ${ }^{13}$. 


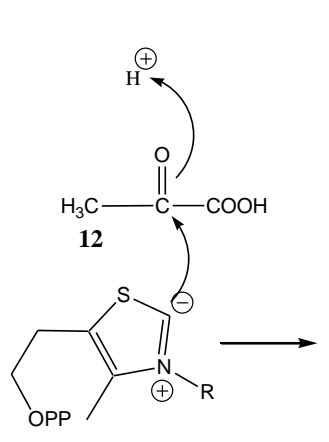

13

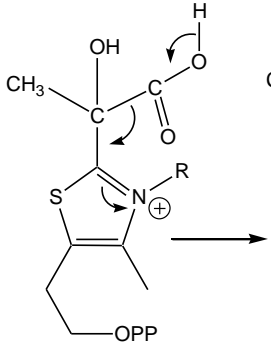

14

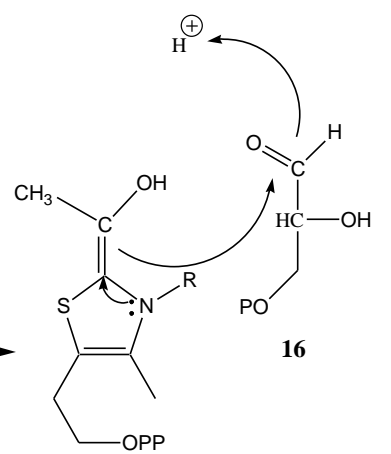

15

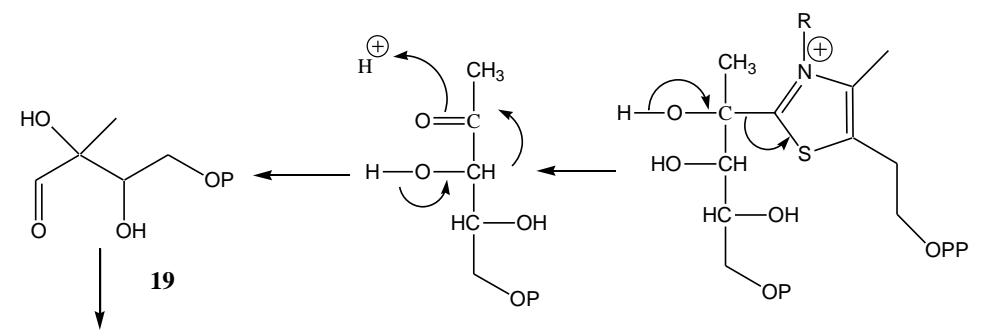

18

17

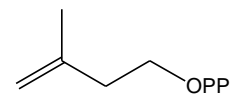

10

Figure 2: Non-mevalonate pathway

\section{THERAPEUTIC USES OF TERPENOIDS}

The fundamental oils firmly impact the life of creepy crawly differently. The basic oils which can be utilized as common bug sprays (bio-insect poisons) are environmentally significant. Tribolium confusum, Rhizopertha domina and Sitophilus cryzae can be incapacitated to the degree of $100 \%$ (and slaughtered up to $80 \%$ ) by the fundamental oils of tansy, cumin, coriander, thyme and absinth. Fundamental oils from tansy and absinth are referred to in regular planting as broad bug sprays. Synergism is noticed, as a combination of basil and eucalyptus oil can kill $100 \%$ of mosquito hatchlings at a focus 2-6 times lower than singular oils. A combination of peppermint (half), camphor (25\%) and coumarin $(25 \%)$ is utilized as an extremely powerful home fumigant. Terpenoids can influence Krebs' cycle, porousness of cell, advancement of callus tissue, improvement of roots and so forth The oil of coriander, angelica and fennel can be poisonous to various developed vegetables, for instance radish by easing back down or halting its germination. Terpene alcohols viz. geraniol, citronellol, menthol and $\alpha$ terpineol may totally stop the germination of different weeds in environmental factors ${ }^{14}$. The xantholides, xanthium and epixanthine confined from the leaves of Xanthium canadens demonstrated exceptional inhibitory movement against the larval development of Drosophila melanogaster ${ }^{15}$. Euponin, a guaianolide segregated from Eupatorium japonicum additionally restrains the development of bugs going about as creepy crawly development controllers ${ }^{16}$. Different basic oils have antifeedants properties. Alantolactone, a sesquiterpene lactone, has been accounted for to go about as an intense antifeedant against the flour bug Tribolium confusum. Fundamental oils likewise go about as creepy crawly attractants, going about as pheromones and can improve the impact of bug sprays when blended in with them. The oils of tree, thyme and coriander are discovered to be solid attractants for food vermins. Fundamental oils show allelopathic poisonous movement, going about as phytotoxins. It has been demonstrated that Salvia leucophylla frees 1,8-cineole, camphor and related mixes through its leaves into the encompassing air and afterward after retention by the dry soil, these mixes repress the germination and development of field spices which would some way or another happen with the appearance of water downpours ${ }^{17}$. Annuithrin, a sesquiterpene lactone segregated from sunflower is accounted for to go about as a plant development inhibitor 18-21. A few fundamental oils structure elements of scents and beauty care products for an enormous scope. Creation of flavor constituents (mono and sesquiterpene) is a trademark highlight of specific families' viz., Poaceae, Myrtaceae, Labiatae, Pinaceae, Rutaceae, Apiaceae, Lauraceae and Asteraceae. Some standard medications containing fundamental oils accordingly or the mixes detached from them are "Terpichol" (herbapol, Poland), utilized for the treatment of nerve stones, nerve bladder, contaminations and liver deficiency. "Rowatinex" (rowa-wagner, Germany) is utilized for the treatment of urocistis, minor plot diseases, renal contaminations and uroliths. "Makatursin" (Makare, Germany) is utilized for the treatment of hack, bronchitis and to advance expectoration. "Vapo-Rub" (Vicks, USA) utilized for the treatment of cattarh, colds and migraines and "Tiger Balm" (China) utilized for the treatment of colds, migraines, rheumatics and strong torments 22 .

\section{REFERENCES:}

1. Yang J, et al. Enhancing production of bio-isoprene using hybrid MVA pathway and isoprene synthase in E. Coli. PLoS One. 2012; $7(4)$.

2. Gershenzon J. The function of terpene natural products in the natural world. Nat Chem Biol. 2007; 3(7):408-414. 
3. Franklin $\mathrm{L}$ et al, Terpene based pesticide treatments for killing terrestrial arthropods including, amongst others, lice, lice eggs, mites and ants. 2001.

4. Perry NSL, et al. In-vitro inhibition of human erythrocyte acetylcholinesterase by salvia Lavandulaefolia essential oil and constituent terpenes. J Pharm Pharmacol. 2000; 52(7):895-902.

5. Carson CF, et al. Melaleuca alternifolia (tea tree) oil: a review of antimicrobial and other medicinal properties. Clin Microbiol Rev. 2006; 19(1):50-62.

6. Bound J, et al. Synthesis and antibacterial properties of 2,3dideoxyglucosides of terpene alcohols and phenols. Food Chem. 2015; 185:192-199.

7. Spurgeon S. R. and Porter J. W. In Biosynthesis of Isoprenoid Compounds; Eds., John Wiley and Sons: New York. 1981.

8. Dewick P. M. Nat. Prod. Rep. 2002; 19:81.

9. Horbach S., Sahm H. and Welle R. Microbiol. Lett. 1993; 115:135.

10. Rohmer M., Sutter B. and Sahm H. J. Chem. Soc. Chem. Commun $1989 ; 1471$

11. Rohmer M., Seemann M., Horbach S., Bringer-Meyer, S. and Sahm, H. J. Amer. Chem. Soc. 1996; 118:2564.
12. Eisenreich W., Sagner S., Zenk M.H. and Bacher A. Tetrahedron Lett. 1997; 38:3889.

13. Adio A. M. Dissertation on Isolation and structure elucidation of sesquiterpenoids from the essential oils of some liverworts (hepaticae), Hamburg. 2005.

14. Brud W. S. and Gora J. Proceedings $11^{\text {th }}$ International Congress of Essential oils, New Delhi, 1989; 2:13.

15. Kawagu K., Nakajina S. and Aliza M. Experimentia 1979; 35:1294.

16. Nakajina S. and Kawagu K. Heterocycles 1989; 10:117.

17. Muller C. H. and Choudhary C. H. Phytochemical Ecology, Academic Press, New York. 1972.

18. Spring O., Albert K. and Gradmann W. Phytochemistry 1981; 20:1883.

19. Cooper W. S. and Stoesz S. Bull. Torr. Bot. Club 1931; 58:67.

20. Centis J. T. and Gottam G. Bull. Torr. Bot. Club 1950; 77:187.

21. Anderson R. C., Katz A. J. and Anderson M. R. J. J. Chem. Ecol. 1978; 4:9.

22. Harborne J. B. Phytochemical Methods, Chapman \& Hall, New York. 1973. 